\title{
ELECTRODEPOSITION OF COPPER IN THE PRESENCE OF AN ACOUSTICALLY EXCITED GAS BUBBLE
}

Douglas G. Offin ${ }^{a}$, Peter R. Birkin ${ }^{* a}$ and Timothy G. Leighton ${ }^{b}$

a School of Chemistry, University of Southampton, Southampton, S017 1BJ United Kingdom

${ }^{b}$ Institute of Sound and Vibration Research, University of Southampton, Southampton, SO17 1BJ United Kingdom

*Corresponding author. e-mail: prb2@soton.ac.uk, Tel: +44 (0)2380594172

\begin{abstract}
Copper has been electrodeposited in the presence of an acoustically excited gas bubble (Ar bubbles with radii $\sim 1.5 \mathrm{~mm}$ held below a copper plate). Under the conditions employed, an acoustic pressure amplitude of $69.5 \mathrm{~Pa}$ is sufficient to excite multiple surface wave modes on the bubble wall. This is observed using high-speed imaging. This oscillation generates significant micromixing, which brings fresh electrolyte to the electrode surface leading to an enhanced deposition current. Scanning electron microscopy (SEM) reveals radial streaming patterns in the resulting copper deposit. Experiments carried out using a lower acoustic pressure amplitude of $50.5 \mathrm{~Pa}$ (such that only the Faraday wave is excited) exhibit a lesser degree of streaming and mass transfer enhancement. No significant enhancement is seen if the bubble is undergoing breathing mode oscillation.
\end{abstract}

Keywords: Electrodeposition, Current enhancement, Bubble, Acoustic excitement, Faraday wave 


\section{Introduction}

The use of sound energy to enhance electrochemical processes is well known, see for example [1-10]. However, in the all these examples, the enhancement is generated through the use of high-intensity ultrasound. In a typical manifestation, "power ultrasound" is generated using a piston-like emitter. These operate at frequencies greater than about $20 \mathrm{kHz}$, to generate high levels of acoustic streaming, together with both inertial and non-inertial cavitation. This leads to extremely high mass transfer coefficients $(0.1-1 \mathrm{~cm}$ $\mathrm{s}^{-1}$ ). These high rates of mass transfer are only encountered when an electrode is placed close to $(<5 \mathrm{~mm})$ the surface of the piston-like emitter. Under these conditions the pressure field generated dictates the highest likelihood of the generation of inertial cavitation [11] and hence these high mass transfer rates may be associated with this phenomenon. However, while these high rates of mass transfer are attractive, the presence of inertial cavitation can lead to problems with erosion [12-14] that may interfere with the desired process. Also, it is known that driving pressure fields in excess of $\sim 100 \mathrm{kPa}$ are required to generate inertial cavitation (under continuous sound irradiation in water and normal temperature and pressure conditions [11, 15]). In alternative approaches, the effects of non-inertial cavitation and acoustic streaming [16] on electrochemical and surface reactions have been reported [17-20]. For example Pocwiardowski et al. employed acoustic streaming in a $500 \mathrm{kHz}$ ultrasonic sound field to influence the electrodeposition of $\mathrm{Cu}$ and $\mathrm{Ni}$ Fe deposits [20]. Nyborg et al. showed, in an eloquent ground breaking study, that microstreaming around an oscillating body (including an acoustically driven gas bubble) could influence the rate of a surface process $[17,18]$. 
Also, it has been shown recently that significant mass transfer enhancements to electrodes can be achieved through the use of targeted acoustic excitement of gas bubbles [21-25]. When gas bubbles are subjected to an applied sound field the bubble undergoes oscillation. Such oscillations of a bubble wall can be thought of as the sum of various modes, corresponding to spherical harmonic perturbations from the spherical stationary position. The 'breathing mode' corresponds to a pulsation (the zero-order spherical harmonic perturbation). It has no threshold for generation, and so always occurs in the presence of a driving sound field, no matter how small. It generates a significant oscillatory change in bubble volume and therefore internal pressure, and so causes the emission of a pressure wave, unlike the higher order modes (the 'shape oscillations'). The shape oscillations have thresholds (in terms of the frequency and amplitude of the driving field) which must be crossed for each mode to be excited. Below the threshold for a given mode, it is not excited. At high driving pressures, many modes are excited and superimposed. The motion of the bubble wall then appears to be chaotic. As the applied pressure amplitude is decreased fewer modes are excited until only one remains. This mode, which has the lowest threshold is called the Faraday wave and leads to a wall oscillation at a frequency which is approximately half the driving frequency. In terms of pressure, the threshold for surface waves is lowest at driving frequencies close to the resonance frequency of the bubble. By targeting the bubble resonance and the excitation of surface waves, low amplitude driving fields $(\sim 100 \mathrm{~Pa})$ can be used to generate mass transfer coefficients of up to $0.05 \mathrm{~cm} \mathrm{~s}^{-1}$. While this is an order of magnitude less than the mass transfer coefficients achievable through the 
use of "power ultrasound", the driving pressures required are $10^{3}$ times lower and in turn the intensity is $10^{6}$ times less than if high intensity ultrasound is employed [21]. This has clear implications for the power requirements of an industrial process if surface waves activity could be scaled up to useful employment on a commercial scale $[21,24]$. It should also be noted that under these conditions, the absence of inertial cavitation events avoids the associated electrode erosion problems [12-14]. This is particularly relevant in this work in which the application of targeted bubble oscillation has been extended to electrodeposition techniques. Clearly the presence of erosive cavitation events in this environment would be counterproductive. In the work presented here, the effect of a single bubble driven to surface wave oscillation on the deposition of copper has been studied. Metal deposition (as part of the electrowinning process) is a vital stage in the refining of a number of metals, for example copper [26], nickel [27] and cobolt [28]. The use of targeted bubble oscillation has the potential to increase the efficiency of such processes, leading to significant reduction in costs and environmental impact. This paper investigates and compares the effect on metal deposition of three different regimes of surface wave activity (i) at a driving amplitude which is sufficiently high to excite many modes; (ii) above the threshold for the Faraday wave but below the threshold for the next mode (so that only the breathing mode and Faraday wave are excited); and (iii) when only the pulsation mode occurs (i.e. below the threshold for the Faraday wave).

\section{Experimental}

The experimental arrangement used in this work is shown in Fig. 1. A custom built cruciform glass cell, constructed from two intersecting glass cylinders (35 
$\mathrm{mm}$ diameter) was used. Three of the arms were terminated with optical windows to allow pictures to be taken, and the fourth (at the top) was left open to allow the cell to be filled with liquid and to insert the electrodes. There was also a hole at the intersection of the arms, to which a Mylar speaker (57 mm diameter, Maplin Electronics) was glued with epoxy resin. Copper depositions were performed potentiostatically from a solution of $0.5 \mathrm{M} \mathrm{CuSO}_{4}$ and $2 \mathrm{M}$ $\mathrm{H}_{2} \mathrm{SO}_{4}$ under aerobic conditions at ambient temperature (ca. $20-25^{\circ} \mathrm{C}$ ). The solution was made using water from a USF Elga Puelab Option E10 water purification system. The working electrodes were $2 \mathrm{~cm} \times 2 \mathrm{~cm}$ copper plates (99.9\%, Advent), to which SEM stubs (Agar) were attached with conducting silver paint and epoxy resin (both $\mathrm{RS}$ ). The back of the working electrodes were then insulated with a clear lacquer. The face of the working electrodes were prepared by sanding with 1200 grade silicon carbide paper and rinsing with copious amounts of water. For each deposition, the working electrode was held using a crocodile clip, which was glued to a glass rod. The use of a crocodile clip (which was in electrical connection with the potentiostat) made it easy to change the working electrode between experiments and the SEM stubs facilitated post-deposition analysis. The glass rod was attached to a computer controlled XYZ rig (Zaber T-LA60 linear actuators and stages), which allowed the working electrode to be positioned in the cell over a $60 \mathrm{~mm}$ travel at $0.1 \mu \mathrm{m}$ resolution in each direction. The working electrode was positioned $10 \mathrm{~mm}$ below the surface of the solution. In order to ensure the SEM stub and crocodile clip were not exposed to the solution, a $5 \mathrm{ml}$ pipette tip was cut to $1.5 \mathrm{~cm}$ length and fitted over SEM stub. It was found that no adhesive was required as the tips were a good fit to the stubs used. The 
counter electrode was a copper disc (32 $\mathrm{mm}$ diameter) and the reference electrode was a saturated calomel electrode (SCE), made in-house. The potential of the working electrode was controlled by means of a potentiostat (Hi-Tek, DT2101) and the current was recorded by a PC via an ADC card (National Instruments PCl-6025E) and software written in-house. For all the depositions reported here, the potential of the working electrode was held at $0.5 \mathrm{~V}$ vs. SCE. The deposition potential was chosen so that the current density in the absence of sonication was approximately $500 \mathrm{~A} \mathrm{~m}^{-2}$, which is similar to those reported in the literature [26, 29]. Bubbles of argon (BOC, Pureshield) were injected under the working electrode using a $19 \mathrm{G}$ needle. Pictures of the bubbles were recorded using a digital high-speed camera (either Mega Speed MS400K or Photron APX RS) fitted with a Navitar 12X Zoom lens. Images of the samples post-deposition were recorded using a Philips XL 30 ESEM. Acoustic pressure measurements were made using a GRAS Type 10CT hydrophone and Brüel \& Kjær Type 2635 charge amplifier via a Tektronix TDS 224 oscilloscope and data transfer software (WaveStar). Pressure measurements were made in the absence of the working electrode and bubble (because of space constraints). The hydrophone was positioned such that the centre of the active element was in the same location as would be occupied by the centre of the bubble. In all cases the measured pressure was sinusoidal and symmetric about zero. The quoted acoustic pressure amplitudes are zero-to-peak values. However, as the pressure was recorded in the absence of the working electrode it cannot be assumed that the quoted pressures are those experienced by the bubble. 


\section{Results and Discussion}

In this work copper has been electrodeposited in the presence of an acoustically excited gas bubble under three different regimes of bubble behaviour. First, at high driving pressure amplitudes such that multiple surface wave modes are excited. Second, above the threshold for the Faraday wave but below the threshold for the next mode (so that only the breathing mode and Faraday wave are excited). Third at a driving pressure below the threshold for the Faraday wave so that only bubble pulsation occurs. The results of this investigation are presented below. First, the bubble behaviour is characterised using high-speed photography and then the effect of bubble oscillation on the copper electro-deposit is discussed.

\section{High-speed photography of excited bubbles}

High-speed images of gas bubbles, taken under the three sets of conditions used are shown in Fig. 2a, b, and c. Fig. 2d shows a stationary bubble for reference. The copper working electrode can be seen as the dark area at the top of each frame. First, the applied sound field had a frequency of 2.0677 $\mathrm{kHz}$ and the acoustic pressure amplitude was $69.5 \mathrm{~Pa}$ (Fig. 2a). This is regime (i). Surface distortions can be seen on the bubble wall. However, there is no clear order. This indicates that several surface wave modes (and the breathing mode) are superimposed. For the second regime of bubble behaviour, the frequency was maintained at $2.0677 \mathrm{kHz}$ but the acoustic pressure amplitude was reduced to $50.5 \mathrm{~Pa}$ (Fig. 2b). Surface distortions can still be seen at the bubble wall under these conditions. However, they appear as peaks around the equator of the bubble, labelled 1-6. This symmetrical distortion shows that under these conditions only the Faraday wave (the 
surface wave mode with the lowest threshold) and the breathing mode are excited. The observation of six peaks in Fig $2 \mathrm{~b}$ suggests that the overall order of the Faraday wave under these conditions is $\sim 12$. This agrees well with theoretical predictions [30]. In regime (iii), the acoustic pressure amplitude was $30.0 \mathrm{~Pa}$, below the threshold for the Faraday wave, such that only the breathing mode was present (Fig. 2c). It is possible to calculate the amplitude of this oscillation [30] and under the conditions employed here it will be small $(\sim 3 \mu \mathrm{m})$. However, the oscillation is evidenced by the fact that the bubble has been attracted towards the rigid copper electrode (see the dotted line in Fig. $2 \mathrm{c}$ and $\mathrm{d}$ ). Attraction of an oscillating bubble towards a rigid surface as a result of acoustic radiation forces is well known [31].

\section{Effect of bubble oscillation on electro-deposit}

The dramatic effect bubble oscillation can have on a copper deposit can be seen in Fig. 3, which shows SEM images of an electrode post-deposition. In this case the deposition was carried out in regime (i). Fig. 3a shows a top view and Fig. 3b shows a view from the side. In the region where the bubble was touching the electrode (shown by the dotted circle in Fig. 3a) no observable deposition has occurred. However, around the bubble the deposition has been greatly enhanced resulting in a 'crater' formation which, in this case, can be seen to extend $\sim 1.2 \mathrm{~mm}$ from the edge of the crater. This enhanced deposition is indicative of bubble-induced micromixing as the result of microstreaming processes. Further examples of micromixing as a result of surface wave activity induced by a sound field can be seen in Fig. 4.26 of reference [32] and Fig. 10 of reference [33]. Here, evidence of this mixing can be seen in Fig. 4, which shows the excited bubble during the deposition 
process. During the deposition a copper-deficient boundary layer exists at the surface of the electrode. The removal of copper from the electrolyte reduces the refractive index of the solution, which is a linear function of concentration [34]. As fresh copper-rich electrolyte is brought towards the electrode surface it mixes with the copper deficient boundary layer. This can be seen in Fig. 4 as dark and light areas in the solution close to the bubble, indicated by the arrows. It should be noted that in the case of Fig. 4, the exposure time used to take the photograph was longer than that used for Fig. 2a $(5.5 \mathrm{~ms}$ compared with $100 \mu \mathrm{s}$ ) and hence the surface distortions on the bubble wall are not clear. Evidence of microstreaming can be seen in the resulting deposit as nodules of growth, which adopt a radial pattern. These are shown in more detail in Fig. $3 \mathrm{c}$ and d. Flow patterns, which are thought to be a direct imprint of the hydrodynamic conditions, have been reported previously in zinc electrodeposited at both rotating disc electrodes [35] and flat plate electrodes in a channel flow cell [36]. In comparison, SEM images of a deposition performed under regime (ii) (single mode excitation) are shown in Fig. 5. The total amount of copper deposited was similar to that deposited on the electrode shown in Fig. 3 (80.3 C passed compared with 84.9 C). However, although there is some evidence of streaming effects (shown in more detail in Fig. $5 b$ and c), the degree of enhanced deposition close to the bubble is less than that seen at the higher pressure amplitude. This difference can also be detected in terms of current density measurements. Fig. 6 shows the current density under various experimental conditions. At all times the potential of the working electrode was maintained at $-0.5 \mathrm{~V} v$ s. SCE and a gas bubble was present on the electrode. The shaded regions indicate times at which sound 
was on. For the first occasion of insonification the pressure amplitude was 50.5 Pa (regime (ii), Faraday wave excitation). The current density can be seen to increase from $480 \mathrm{~A} \mathrm{~m}^{-2}$ to $525 \mathrm{~A} \mathrm{~m}^{-2}$ (a $9 \%$ increase). For the second insonification period the pressure amplitude was increased to $69.5 \mathrm{~Pa}$ (regime (i), multiple surface wave excitation). On this occasion the current density changed from $470 \mathrm{~A} \mathrm{~m}^{-2}$ to $545 \mathrm{~A} \mathrm{~m}^{-2}$ (a $16 \%$ increase). It was found that deposition under the conditions of regime (iii) showed no observable change in the current density. This confirms that the excitation of multiple surface wave modes leads to a greater degree of mass transfer enhancement. However, it should be noted that the nature of the experimental setup will underestimate this effect in terms of the current densities that are measured. The current densities reported here represent the average response, both temporally and spatially. The currents measured relate to the whole electrode area $\left(4 \mathrm{~cm}^{2}\right)$. However, the micromixing effect is limited to a region close to the oscillating bubble. Inspection of Fig. $3 a$ and $5 a$ indicates that the region in which enhanced deposition has occurred extents $\sim 1.2 \mathrm{~mm}$ from the edge of the region in which no observable deposition has occurred. This means that the area of the electrode exposed to the enhanced mass transfer can be estimated as $\sim 0.13 \mathrm{~cm}^{2}$, which represents only $\sim 3 \%$ of the total electrode surface. This implies that the enhancement in mass transfer in the active zone around the bubble is many times larger than that suggested by the electrochemical data. This is supported by recent work, which employed microelectrodes, held under mass transfer limiting conditions, positioned close to the equator of an oscillating bubble [21-23]. The use of microelectrodes facilitated a high degree of spatial and temporal resolution. It was found that 
when the electrode was placed close to a bubble wall $(<200 \mu \mathrm{m})$ the excitation of surface waves caused an increase of more than $500 \%$ in the observed current $[21,22]$. The distance dependence of the enhancement was also investigated and it was found that significant current enhancement could be detected up to ca. 1 bubble radius away from the gas/liquid interface [21]. This agrees well with the region of enhanced deposition observed here. It is also worth noting that the microelectrode was able to detect enhancements due to the breathing mode of the bubble $[23,25]$. These were not detected in the work reported here. However, the enhancements detected at the microelectrode were relatively small compared with those induced by surface wave oscillation ( $50 \%$ compared with > $500 \%$ ) when measured close ( 5$10 \mu \mathrm{m})$ to the bubble wall $[23,25]$. It is therefore not surprising that no enhancement was detected in the work reported here due to spatial averaging effects.

\section{Conclusions}

Copper has been electrodeposited in the presence of an acoustically excited bubble. Under the conditions used here (Ar bubbles with radii of $\sim 1.5 \mathrm{~mm}$ held under a copper plate) multiple surface wave modes are excited at acoustic pressure amplitudes of $\sim 70 \mathrm{~Pa}$. It has been shown that this generates significant micromixing close to the electrode surface and enhances the deposition current. However, radial streaming patterns, which are visible in the resulting deposit, indicate that this effect is limited to a small region close to the bubble. At lower acoustic pressure amplitudes (50.5 Pa, such that only the Faraday wave is excited) micromixing/streaming and enhanced current densities are observed to a lesser extent. It was found that 
if the acoustic pressure amplitude was less than the threshold for surface waves no spatially averaged current enhancement was observed.

\section{Acknowledgements}

We thank EPSRC for funding to support DGO under grant GR/S78698/01 and EP/D05849X/1 for equipment.

\section{Figure Legends}

Figure 1 Experimental setup

Figure 2 Images showing a gas bubble held below a copper plate in a solution of $0.5 \mathrm{M}$ $\mathrm{CuSO}_{4}$ in $2 \mathrm{M} \mathrm{H}_{2} \mathrm{SO}_{4}$ under various experimental conditions. (a) Regime (i). Frequency = $2.0677 \mathrm{kHz}, P_{A}=69.5 \mathrm{~Pa}$, exposure time $=100 \mu \mathrm{s}$ (b) Regime (ii). Frequency $=2.0677 \mathrm{kHz}$, $P_{A}=50.5 \mathrm{~Pa}$, exposure time $=100 \mu \mathrm{s}$ (c) Regime (iii). Frequency $=2.0677 \mathrm{kHz}, P_{A}=30.0$ $\mathrm{Pa}$, exposure time $=5.5 \mathrm{~ms}$. (d) No sound, exposure time $=5.5 \mathrm{~ms}$. The scale bar in (a) represents $2 \mathrm{~mm}$.

Figure 3 SEM images showing copper deposited on an electrode in the presence of an acoustically excited bubble under regime (i) (see main text for details). The acoustic pressure amplitude was $69.5 \mathrm{~Pa}$. and the frequency was $2.0677 \mathrm{kHz}$. The electrode was held at $-0.5 \mathrm{~V}$ vs. SCE in a solution of $0.5 \mathrm{M} \mathrm{CuSO}_{4}$ in $2 \mathrm{M} \mathrm{H}_{2} \mathrm{SO}_{4}$. A total charge of $84.9 \mathrm{C}$ was passed at an average current density of $607 \mathrm{~A} \mathrm{~m}^{-2}$. (a), (c) and (d) are from above. (b) is from the side. The scale bar in (b) represents $1 \mathrm{~mm}$ (also applies to (a)). The scale bars is (c) and (d) represent $100 \mu \mathrm{m}$ and $20 \mu \mathrm{m}$ respectively.

Figure 4 Image (exposure time $=5.5 \mathrm{~ms}$ ) showing a gas bubble held below a copper electrode in a solution of $0.5 \mathrm{M} \mathrm{CuSO}_{4}$ in $2 \mathrm{M} \mathrm{H}_{2} \mathrm{SO}_{4}$. The electrode was held at $-0.5 \mathrm{~V} v s$. SCE. The scale bar in represents $2 \mathrm{~mm}$.

Figure 5 SEM images showing the copper deposited on an electrode in the presence of an acoustically excited bubble under regime (ii) (see main text for details). The pressure was $50.5 \mathrm{~Pa}$ and the frequency was $2.0677 \mathrm{kHz}$. The electrode was held at $-0.5 \mathrm{~V} v \mathrm{v}$. SCE in a solution of $0.5 \mathrm{M} \mathrm{CuSO}_{4}$ in $2 \mathrm{M} \mathrm{H}_{2} \mathrm{SO}_{4}$. A total charge of $80.3 \mathrm{C}$ was passed at an average 
current density of $559 \mathrm{~A} \mathrm{~m}^{-2}$. The scale bars in (a), (b) and (c) represent $1 \mathrm{~mm}, 200 \mu \mathrm{m}$ and $20 \mu \mathrm{m}$ respectively.

Figure 6 Plot showing the current density at a $4 \mathrm{~cm}^{2}$ copper electrode held at $-0.5 \mathrm{vs}$. SCE as a function of time under various experimental conditions. Shaded regions indicate times at which sound $(2.0677 \mathrm{kHz}$, see figure for pressure) was on.

\section{References}

1. P. R. Birkin, S. Silva-Martinez, J. Electroanal. Chem., 416, (1996), 127.

2. R. G. Compton, J. C. Eklund, F. Marken, T. O. Rebbitt, R. P. Akkermans, D. N. Waller, Electrochimica Acta, 42, (1997), 2919.

3. R. G. Compton, J. C. Eklund, S. D. Page, T. J. Mason, D. J. Walton, J. Appl. Electrochem., 26, (1996), 1775.

4. R. G. Compton, J. C. Eklund, D. N. Waller, F. Marken, Electrochimica Acta, 41, (1996), 315.

5. $\quad$ C. R. S. Hagan, L. A. Coury, Anal. Chem., 66, (1994), 399.

6. J. L. Hardcastle, J. C. Ball, Q. Hong, F. Marken, R. G. Compton, S. D. Bull, S. G. Davies, Ultrason. Sonochem., 7, (2000), 7.

7. F. Javier Del Campo, J. Melville, J. L. Hardcastle, R. G. Compton, J. Phys. Chem. A, 105, (2001), 666.

8. J. Klima, C. Bernard, C. Degrand, J. Electroanal. Chem., 367, (1994), 297.

9. J. Klima, C. Bernard, C. Degrand, J. Electroanal. Chem., 399, (1995), 147.

10. J. Reisse, H. Francois, J. Vandercammen, O. Fabre, A. Kirsh-de Mesmaeker, C. Maerschalk, J.-L. Delplancke, Electrochimica Acta, 39, (1994), 37.

11. P. R. Birkin, D. G. Offin, T. G. Leighton, PCCP, 7, (2005), 530.

12. P. R. Birkin, D. G. Offin, T. G. Leighton, Wear, 258, (2005), 623.

13. P. R. Birkin, D. G. Offin, T. G. Leighton, Electrochem Commun., 6, (2004), 1174.

14. P. R. Birkin, R. O'Connor, C. Rapple, S. Silva-Martinez, J. Chem. Soc., Faraday Trans., 94, (1998), 3365.

15. C. K. Holland, R. E. Apfel, IEEE Trans. Ultrason. Ferr., 36, (1989), 204.

16. W. L. Nyborg, Acoustic Streaming. W. P. Mason, Ed., In Physical Acoustics Principles and Methods Academic Press, New York, 1965.

17. F. J. Jackson, W. L. Nyborg, J. Acoust. Soc. Am., 30, (1958), 614.

18. W. L. Nyborg, R. K. Gould, F. J. Jackson, J. Acoust. Soc. Am., 31, (1959), 706.

19. W. L. Nyborg, M. I. L. Seegall, Effects of acoustic microstreaming at electrodes, Proceedings of 3rd International Congress on Acoustics, Elsevier, (1960) 346-348.

20. P. Pocwiardowski, H. Lasota, C. Ravn, Acta Acust. United Acust., 91, (2005), 365.

21. P. R. Birkin, Y. E. Watson, T. G. Leighton, J. Chem. Soc., Chem. Commun., (2001), 2650. 
22. P. R. Birkin, Y. E. Watson, T. G. Leighton, K. L. Smith, Langmuir, 18, (2002), 2135.

23. Y. E. Watson, P. R. Birkin, T. G. Leighton, Ultrason. Sonochem., 10, (2003), 65.

24. T. G. Leighton, Int. J. Mod. Phys. B, 18, (2004), 3267.

25. Y. E. Watson, Electrochemical investigations of acoustically driven gas bubbles, PhD Thesis, University of Southampton (2003).

26. W. C. Cooper, J. App. Electrochem, 15, (1985), 789.

27. R. R. Moskalyk, A. M. Alfantazi, Miner. Eng., 15, (2002), 593.

28. R. R. Moskalyk, A. M. Alfantazi, Miner. Metall. Proc., 17, (2000), 205.

29. G. D. Rigby, P. E. Grazier, A. D. Stuart, E. P. Smithson, Chem. Eng. Sci., 56, (2001), 6329.

30. D. G. Ramble, A. D. Phelps, T. G. Leighton, Acustica, 84, (1998), 986.

31. T. G. Leighton, The Acoustic Bubble, Academic Press Limited, London, 1994, 168-172.

32. T. G. Leighton, The Acoustic Bubble, Academic Press Limited, London, 1994.

33. T. G. Leighton, Prog. Biophys. Mol. Bio., (In Press).

34. CRC Handbook of Chemistry and Physics. R. C. Weast, Ed. CRC Press, Cleveland, 1975.

35. M. M. Jaksic, J. Electroanal. Chem., 249, (1988), 63.

36. M. M. Jaksic, J. Electroanal. Chem., 249, (1988), 35. 


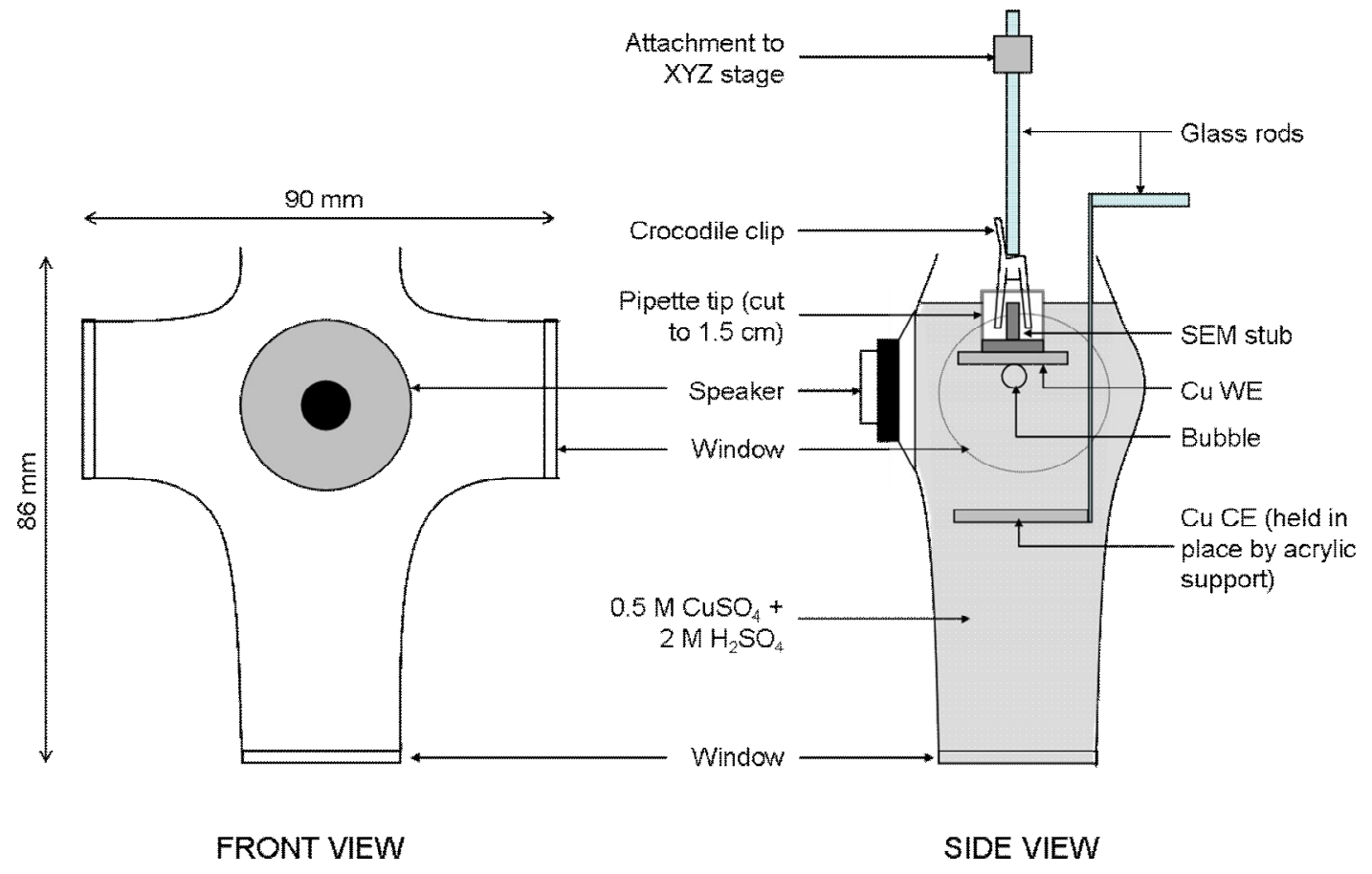

Figure 7 


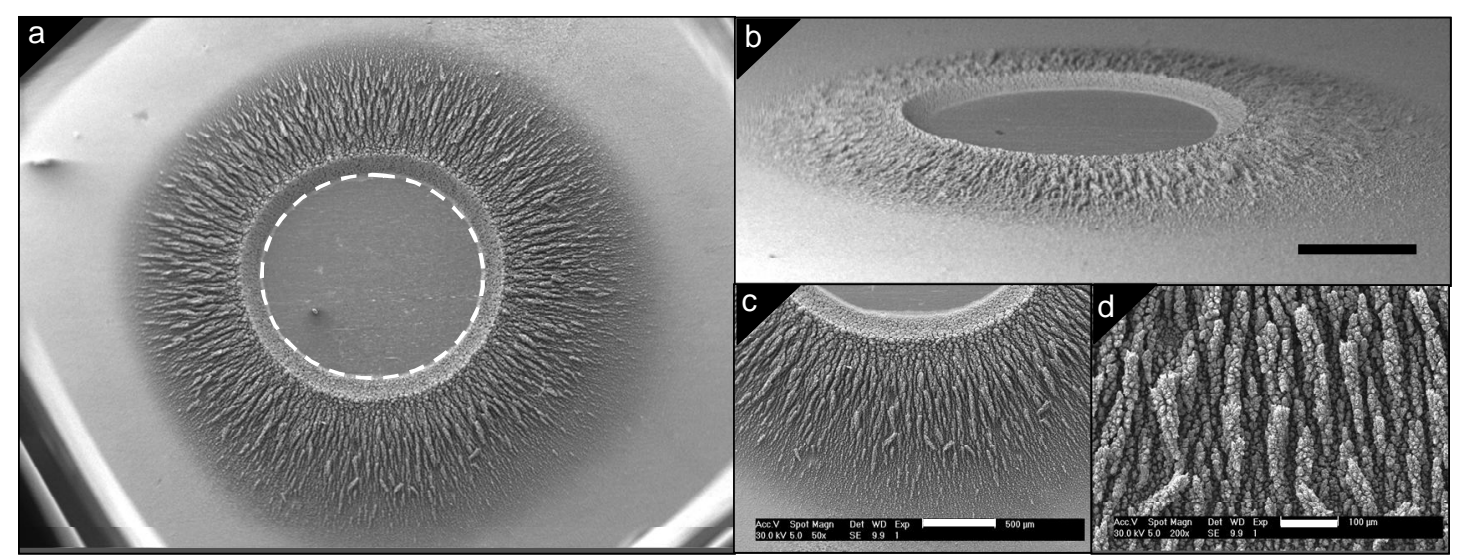

Figure 8 


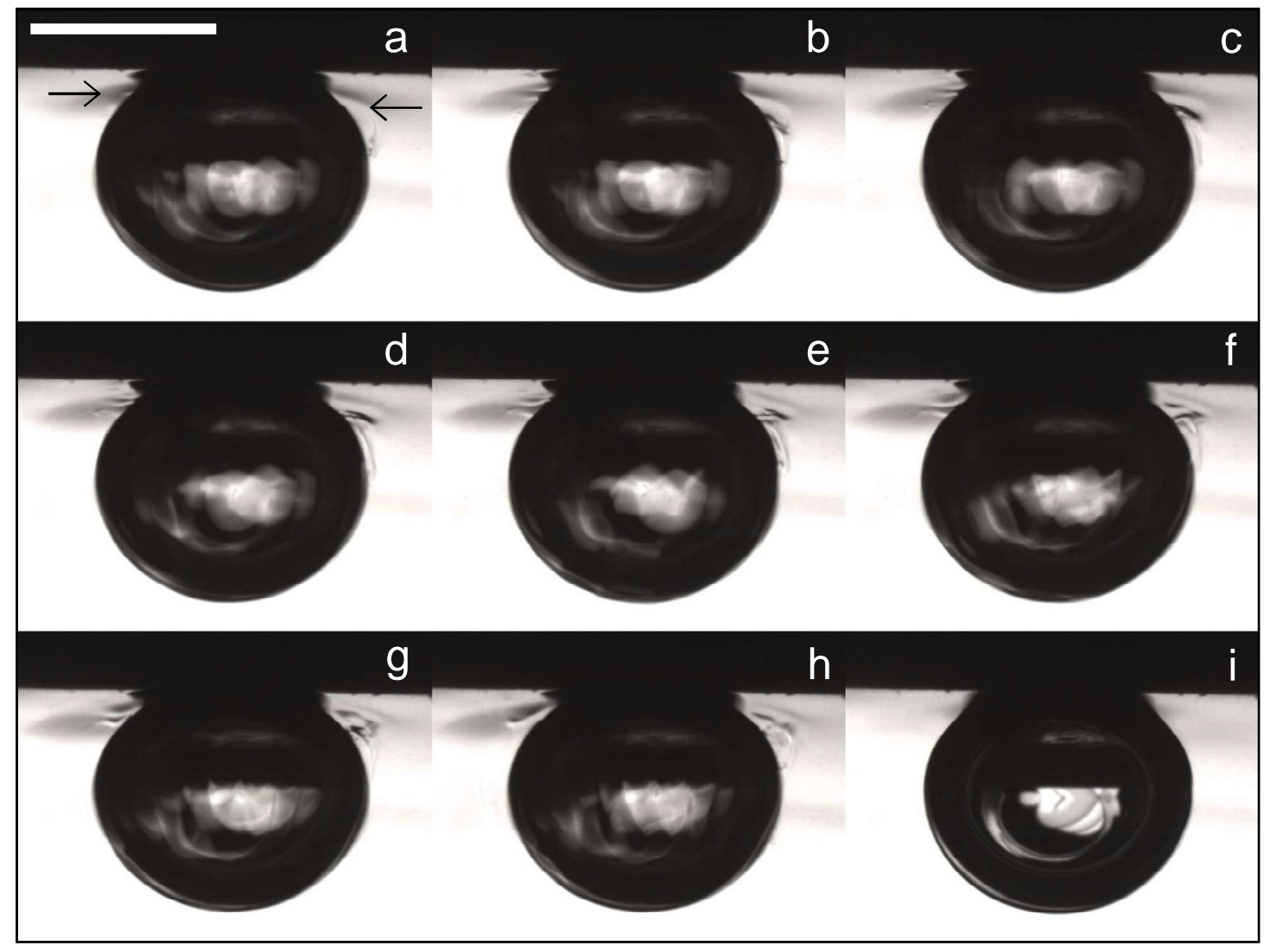

Figure 9 


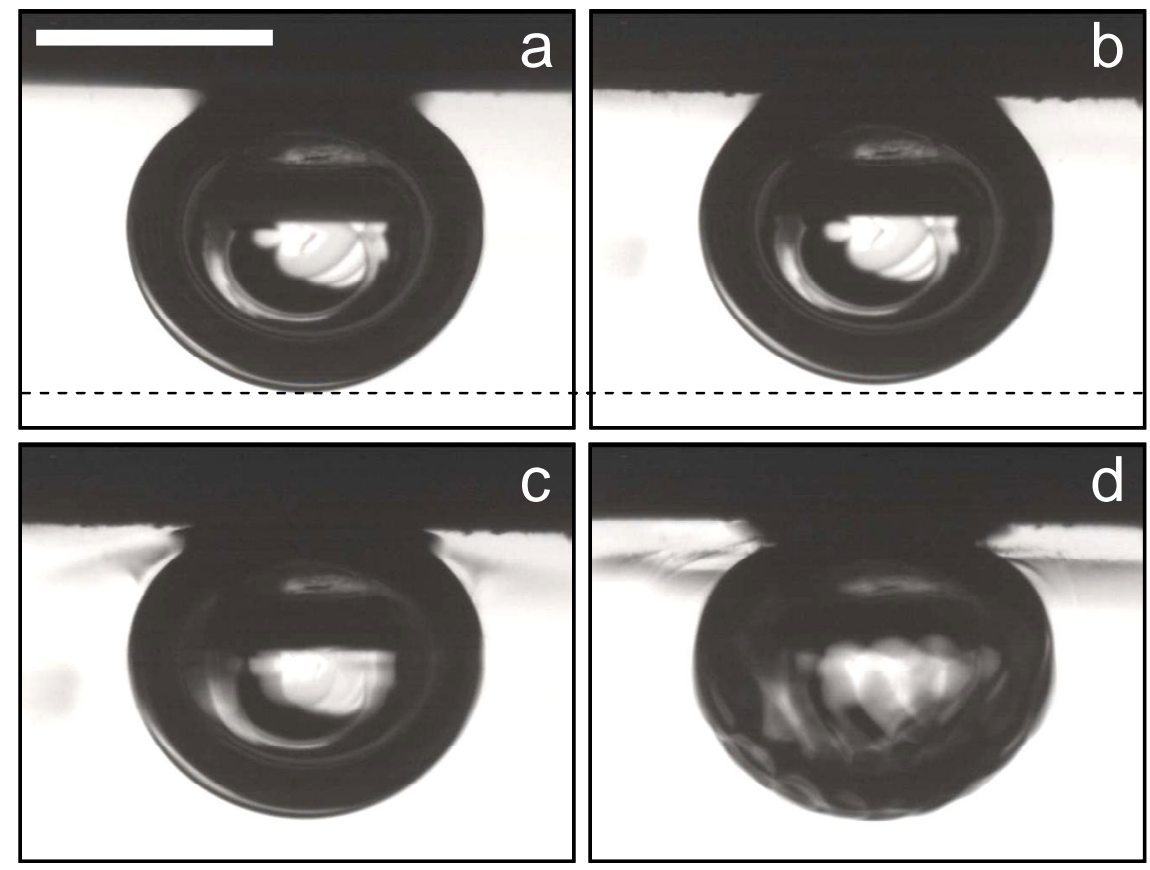

Figure 10 


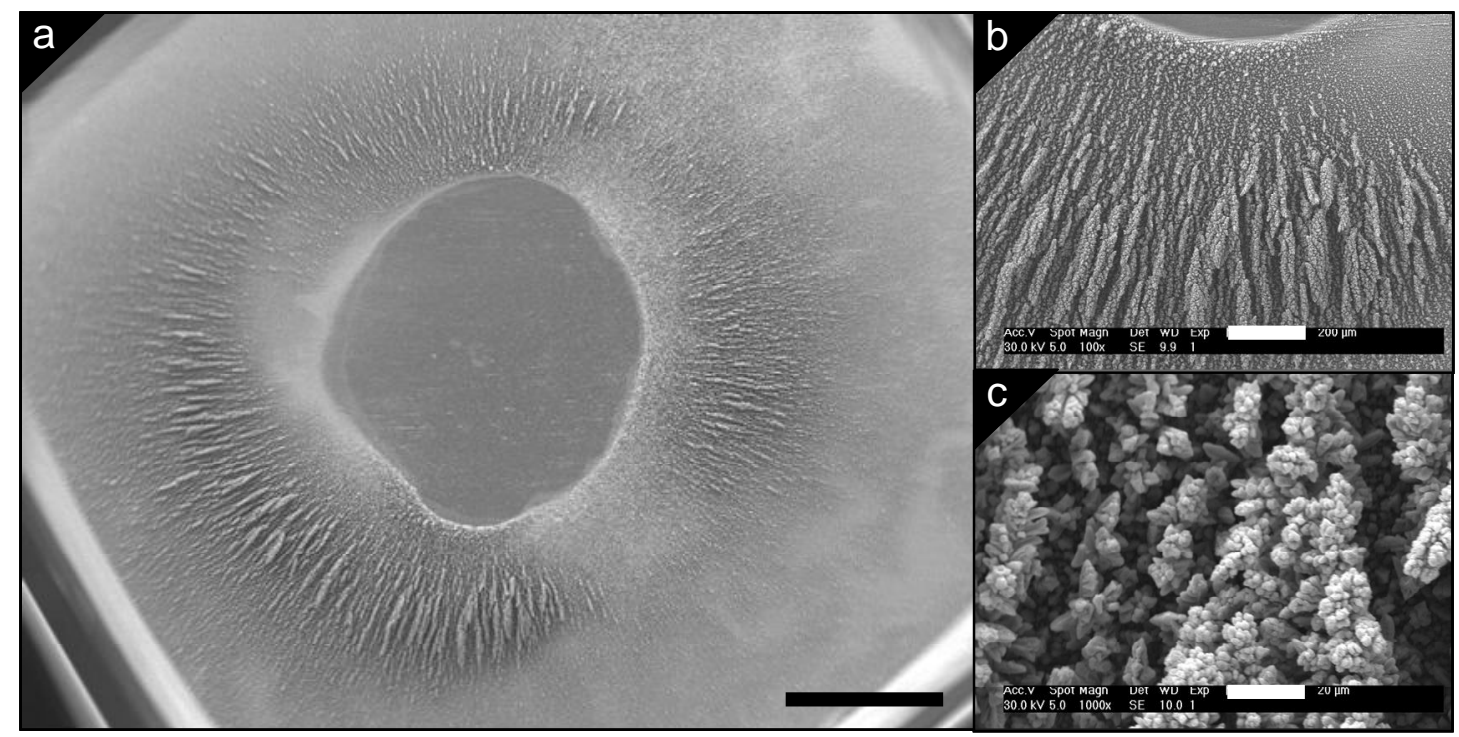

Figure 11 


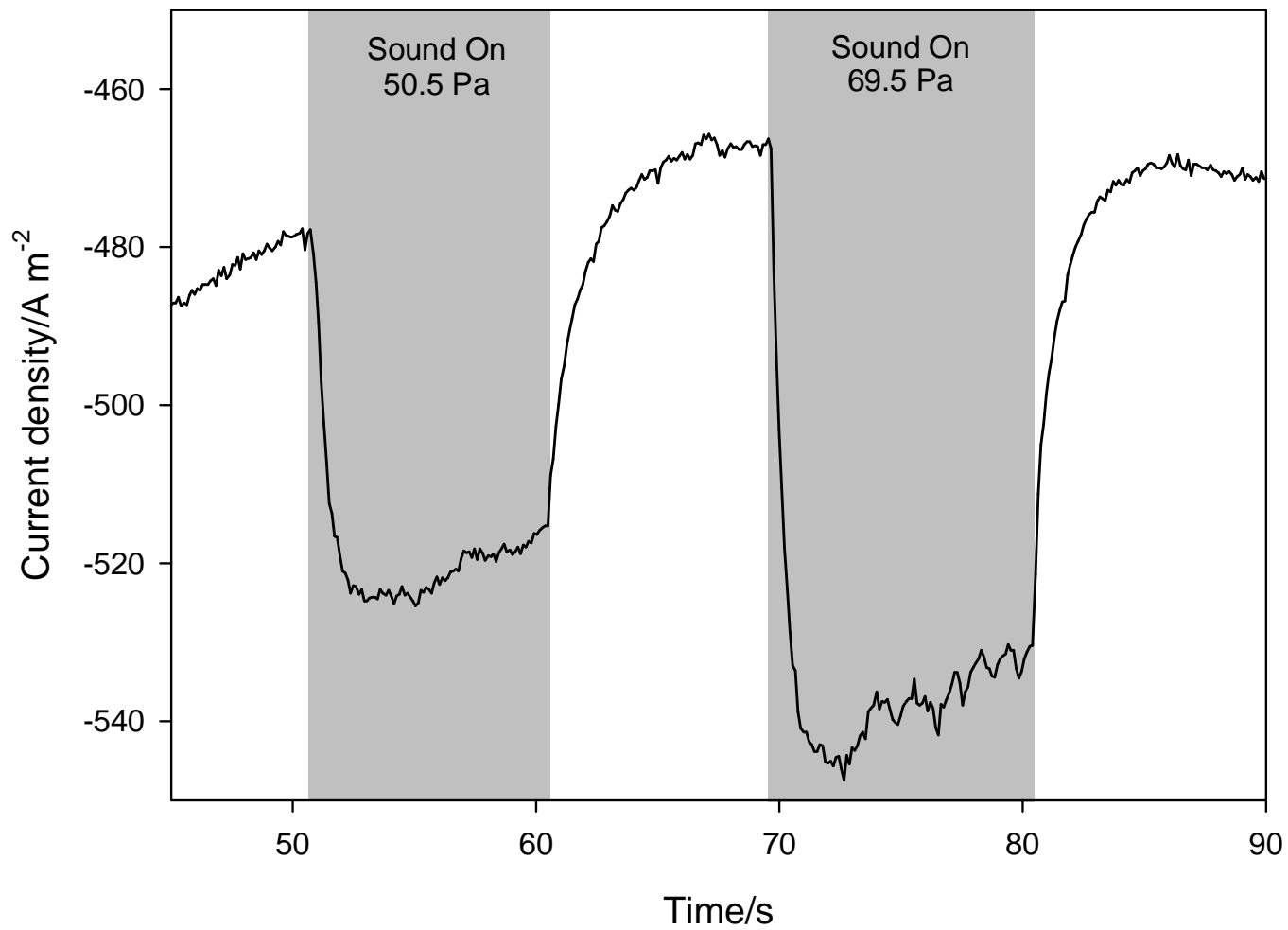

Figure 12 